\title{
Report urges UK universities to recoup full overhead costs
}

London. A new report on research in British universities offers a novel solution to a perennial problem: with too little money to go around, universities should do less research and charge sponsors the full amount - up to 40 per cent more than at present of their overhead costs. It also says that universities should show greater concern for the growing proportion of their staff on short-term contracts.

The recommendations in the report (The Science Base: Research in Universities, HMSO, £25), from the Advisory Council buildings and replacing equipment to shore up research. Nicholson says that the resulting imbalance between available funds and potential research must be addressed in the next five years, and that this can be done only with less research and greater support for what is being done in the laboratory.

The recommendation for claiming full overheads is in line with the views of the Committee of Vice-Chancellors and Principals (CVCP), which has long said that university budgets intended for teaching and infrastructure maintenance are subsidizing

\section{Ratio of short-term to permanent appointments rising at UK universities}

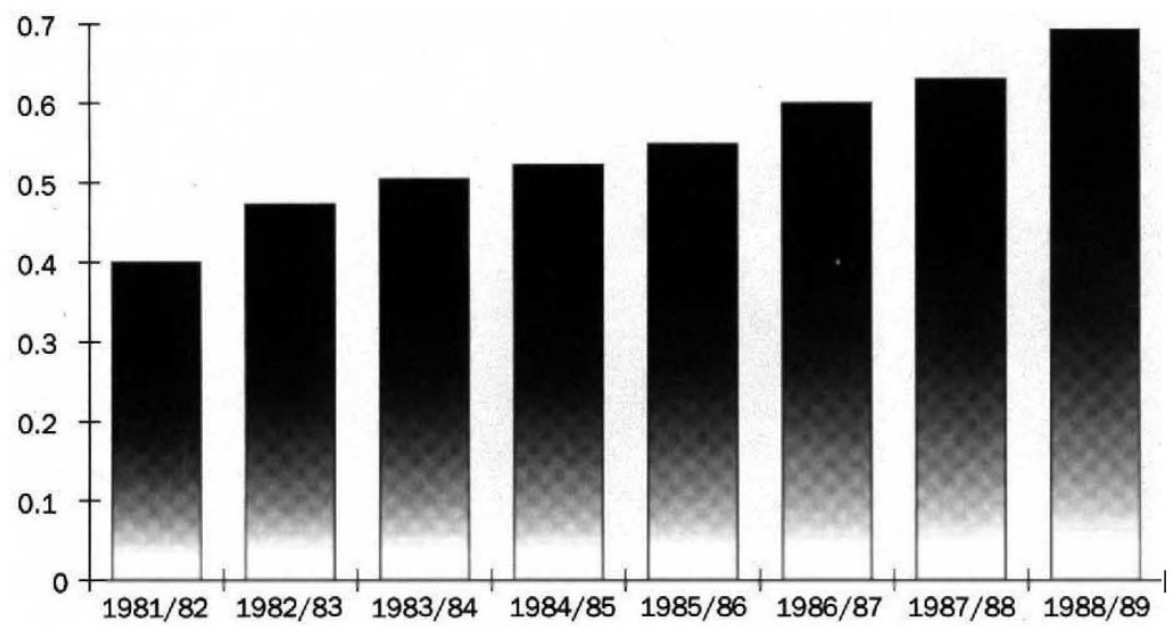

on Science and Technology (ACOST) have been welcomed, with varying degrees of caution. The government has so far been silent on the request from the ACOST chairman, Sir Robin Nicholson, that it should spend "hundreds of millions of pounds" more to establish a viable science base in Britain, but has promised a response by the end of the year.

The report offers three reasons for the current crisis. Although total research funding increased by more than 30 per cent in real terms during the $1980 \mathrm{~s}$, and funding from nongovernment sources has almost doubled, that money buys much less research than in the past. This is because science has become more expensive as it has become more sophisticated. In addition, more researchers are competing for grants in pursuit of an expanding scientific frontier. Moreover, universities generally do not recover the full cost of what they spend to support their researchers.

The university system is cracking under this strain, diverting money from repairing research. CVCP spokesman Ted Nield says that university administrators would prefer to have fewer research projects than research that "impoverishes" its host institute.

But charities such as the Cancer Research Campaign and the British Heart Association, the major source for universities of project grants in biomedical sciences, are offended by the suggestion that they should pay indirect costs, which could add 40 per cent to their bill. Donors are less likely to continue support if they believe that a large portion of their cash will not be funding their chosen work. In addition, the type of research the charities undertake would suffer because in many cases, for example cystic fibrosis, they are the only funding agency.

June Clarke, grants administrator at the University of Oxford, sides with the charities. "Unlike industry, charities tend to be approached by universities, not the other way round", she says. "If you're going out with a begging bowl, it's better to show you're willing to put in your own funds as well."

The report also addresses the problem of short-term contract research workers, whose numbers have grown in inverse proportion to their career prospects. According to 1990 figures, short-term posts now make up 42 per cent of all science posts in universities, compared with 22 per cent in 1978 . Because a credible career structure for researchers does not exist, universities are no longer able to attract the best scientists.

The report recommends that universities should avoid offering repeated short-term contract renewals if those concerned are unlikely to be hired permanently. It also says that the salary gap between scientific and nonscientific disciplines in universities should be narrowed to reflect outside pay more closely.

These comments have been criticized as unrealistic by the research community and by university officials. Christine Knowles of the Association of University Teachers says that she welcomes attention being drawn to the problem but does not know how the recommendations would be implemented. The small number of permanent posts available do not match the large number of researchers on contract, says Nield. And neither believes that differential pay would help to solve a problem that is not rooted in financial rewards.

Alison Abbott

\section{British Petroleum to slash US and UK research staff}

London. British Petroleum (BP) has announced plans to shed nearly half its research staff in a merger of its research and engineering divisions. The move will save the company $\$ 180$ million a year.

Spokesman Roddy Kennedy says that BP's research organization, mostly concentrated at two centres in Sunbury, England, and Cleveland, Ohio, was designed for a much bigger corporation. Having recently shed many of its core businesses, a streamlined BP does not need to support such a large research team, he says. More than 40 per cent of BP's 2,200 researchers will be handed redundancy notices in October, when details of the proposed plans are announced.

Streamlining goes hand in hand with a change in policy, initiated more than five years ago, to make research more commercially orientated. At that time, BP's former policy of including some basic research projects in its in-house programme was abandoned in favour of funding university research. Academic research support will not be affected by the cutbacks. In fact, BP is expected to buy in more expertise in the future, says Kennedy.

Alison Abbott 